\title{
MEMORIA Y VÍCTIMAS EN LAS TESIS SOBRE EL CONCEPTO DE HISTORIA DE WALTER BENJAMIN: CONTRA LA VIOLENCIA DEL OLVIDO
}

\author{
Memory and victims in the theses on the concept of history of Walter Benjamin: \\ against the violence of forgetting
}

\author{
Cristóbal Arteta Ripoll ${ }^{1}$, Juliana Paola Díaz Quintero ${ }^{2}$
}

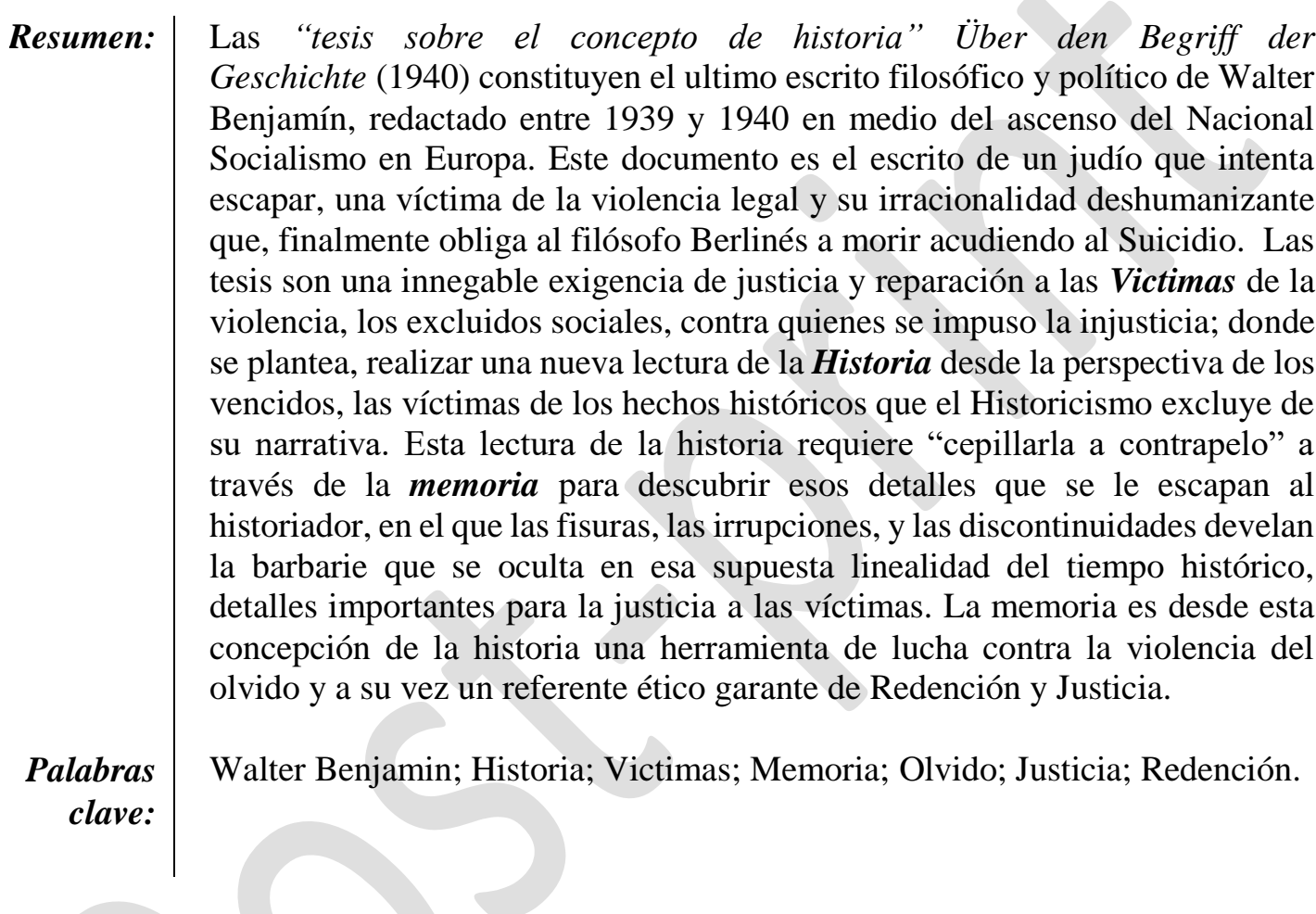

Abstract: The theses about the concept of history Uber dan Begriffder Geschhicte (1940) are the last philosophic and political papers edited by Walter Benjamin, written between 1939 and 1940 in the middle of the National Socialism rise in Europe. This is the brief of a Jewish that tries to escape, a victim of the legal violence and its irrational dehumanization that finally obliges the philosopher of Berlin to commit suicide. The theses are a clear demand for justice and compensation for the Victims of violence, those who are socially excluded, against whom injustice was impelled, where a new interpretation of History is proposed, from the standpoint of the defeated, the victims of the historic facts that History takes out of its narrative. This reading of history requires "a brush against the grain" through memory in order to disclose those details that escape the historian where the holes, invasions and discontinuities show the barbarism that is hidden in this supposed linearity of the historic time, important details for the victim`s justice. The memory is from this conception of history the tool for the struggle against

\footnotetext{
${ }^{1}$ Docente investigador Universidad del Atlántico- Universidad Libre. Asesor de investigaciones USB. Correo: cristobalartetar@gmail.com

${ }^{2}$ Magister en Filosofía, Universidad Federal de Uberlandia. Becada OEA 2018.
} 
violence of oblivion and at the same time an ethic guarantee of Redemption and Justice.

Keywords: $\quad$ Walter Benjamin; History; Victims; Memory; Forgetfulness; Justice; Redemption.

Fecha Recibido: $12 / a g o / 2020$

Fecha Aceptado: 05/oct/2020

\section{"TESIS SOBRE EL CONCEPTO DE HISTORIA"}

Las "tesis sobre el concepto de historia" de Walter Benjamin son consideradas como uno de los textos filosóficos y políticos más importantes del siglo XX. Este texto inacabado, podría considerarse como un tratado a la memoria de las víctimas, "Benjamin en efecto, propone una lectura de la historia que halla en la Memoria el elemento de constitución: mirar la historia desde el prisma de los vencidos; entonces, seguramente la historia se escribiría de otro modo, tendría otro libreto, actuarían otros protagonistas, se describirían otros proyectos, se narrarían otros sueños, se pondría en definitiva de manifiesto que "hubo otro" rumbo. (Rivera y Bergalli, 2010, p,29)

Estas tesis, constituyen el último texto de Walter Benjamin, "redactadas bajo el impacto del estallido de la segunda guerra mundial y del tratado germánico-soviético, el cual, hasta cierto punto, lo había hecho posible" (Vélez, 1999, p.45). Siendo un defensor de los postulados Marxistas de la lucha de clases, admite su decepción frente a la omisión en la acción y la crítica de los Comunistas Rusos al mando de Stalin, en torno al movimiento Nazi. "Benjamin parte del doloroso reconocimiento de que todo el movimiento histórico conocido desde mediados del siglo XIX como revolución comunista o socialista ha terminado por ser un intento fracasado". (Echevarría, s/f, p. 6).

Es esta una de las razones que lo motiva a construir una nueva concepción de la historia, un nuevo discurso que toma los elementos marxistas y mesiánicos para pensarse realmente la emancipación de los oprimidos en términos políticos y culturales; que se da mediante la irrupción del continuum de la historia. “(..) En las pocas diez páginas de esta obra se imagina lo que podría ser o lo que debería ser el núcleo de un discurso socialista o comunista diferente (...), verdaderamente histórico, y verdaderamente materialista, el discurso revolucionario adecuado a la época del ocaso de la modernidad capitalista. (Echevarría, s/f, p. 6).

Es importante mencionar el contexto bajo el cual se desarrollan las tesis, caracterizado el momento histórico por "la conquista nacionalsocialista" como lugar donde se desarrolla con mayor intensidad la banalización de la vida, el antisemitismo y los campos de 
concentración de la Alemania Nazi, sinónimo de crímenes con su marca imborrable para la posteridad. Como lo señala Giorgio Agamben (Roma,1942) en con esos campos el modelo de la modernidad entra en crisis. El estado de excepción se hace permanente reduciendo a los individuos a nuda vida, es decir a pura existencia biológica. Allí no solo fueron víctimas los judíos sino también aquellos que no cumplían con las exigencias de la de la "raza aria", tales como los propios alemanes con deformaciones genéticas o prisioneros políticos. El individuo es convertido en un homo sacer, es decir, en un individuo cuya muerte a pesar de no estar fijada por ningún ordenamiento jurídico, su significado ni contiene ni expresa ningún delito. Así la vida aparece frente al poder como un mero residuo biológico, libremente dispuesto sin importar su cultura, lengua o tradición. Para Agamben, el campo de concentración es el paradigma límite que da inicio y final a la práctica política contemporánea. (Homo sacer, 1995).

Cabe mencionar que Benjamin también fue víctima del desprecio intelectual de las instituciones alemanas, borrachas de nazismo que lo amedrantaron, lo persiguieron, lo lanzaron al exilio errante y lo llevaron al suicidio en Portbou, un pueblo perdido de la frontera hispanofrancesa, el 26 de septiembre de 1940...

Benjamín en sus obras tiene plena claridad de cuál es el sujeto de su defensa y no duda ni un instante en señalarlo: es el oprimido, el vencido, el lumpen o el históricamente invisibilizado. Su crítica de la historia no permite que se pueda tener continuidad en el tiempo, si detrás de éste, dejamos cadáveres y proyectos inconclusos, si además de ello no tenemos plena conciencia de la responsabilidad que tiene el filósofo o el historiador, el artista o el político como testigo de una verdad, de unos hechos, que el relato del vencedor ha excluido de la historia oficial, y que además se impone como verdad única respecto al pasado.

Una lectura de las tesis nos permite ver esos espacios de la memoria de las víctimas y la importante labor del historiador, del materialista histórico, del marxista comprometido con la praxis política, en la lucha revolucionaria entre vencedores y oprimidos que busca sacar del anonimato al "oprimido" y que busca romper ese continuo de la historia que en la visión de Benjamin no es otro que el de catástrofe y barbarie.

Michael Lowy hace un interesante estudio sobre la obra de Benjamín en un texto intitulado Walter Benjaiin, aviso de incendio, en él, dedica un capítulo a las tesis, llamado Una lectura de las tesis del concepto de historia de Walter Benjamin, donde se exponen diversas interpretaciones que se tienen respecto a éllas y que utilizaremos a continuación como punto de referencia para abordar el estudio sobre la importancia de la Memoria y las Víctimas en este punto de la obra de Benjamín. 


\section{Comencemos por la tesis II:}

Uno de los rasgos más sorprendentes del alma humana, junto a tanto egoísmo en el detalle es que "el presente, en general, carece de codicia en cuanto a su futuro". Esta reflexión de Lotze, induce a pensar que nuestra imagen de felicidad está íntegramente marcada por el tiempo al que nos ha relegado hoy el curso de nuestra propia existencia, (...), en otras palabras, la imagen de felicidad es inseparable de la imagen de liberación. Ocurre lo mismo con la imagen del pasado que la historia hace suya. El pasado trae consigo un índice secreto que lo remite a la redención. (...) existe un acuerdo tácito entre las generaciones pasadas y la nuestra. Nos han aguardado en la tierra. Se nos concedió como a cada generación precedente una débil fuerza mesiánica sobre la cual el pasado hace valer una pretensión. Es justo no ignorar esa pretensión. Cualquiera que profese el materialismo histórico sabe algo de ella". (Benjamin en: Lowy, 2003, p, 54-55).

Michael Lowy muy acertadamente propone aclarar el significado de algunos conceptos teológicos que son frecuentemente utilizados por Benjamín y que hacen parte de su tradición religiosa "el judaísmo". Una de estas categorías es la redención (redemption), "Benjamin la sitúa, ante todo, en la esfera del individuo: su felicidad personal implica la redención de su propio pasado, la realización de lo que habría podido ser y no fue" (Lowy, 2003, p 55). Esta felicidad implica la reparación, reparar el abandono y la desolación en la que se ha sumido a las víctimas del pasado. "la redención del pasado no es otra cosa que esa realización y esa reparación, según la imagen de la felicidad de cada individuo y de cada generación" (Lowy, 2003, p 55). Redención íntimamente vinculada al rescate de la esperanza, de las utopías perdidas a causa de los horrores de la guerra, donde el espíritu saca la fuerza de la desesperanza.

La concepción de la historia que tiene Benjamin no concibe como anteriormente mencionábamos, que el daño ocasionado a las generaciones pasadas no sea reparado, y que, además, aquella causa que dio origen a dicha violencia no sea cuestionada por las generaciones del presente. En este sentido la redención tiene un carácter de "rememoración histórica de las víctimas del pasado". La memoria cumple la función de ser puente que une pasado y presente, reaviva el pasado a través de la recordación con el objetivo de criticar la injusticia y remover la conciencia ética; en aras de rechazar la violencia ejercida contra el otro. "No hay justicia sin memoria de la Injusticia. habría entonces que plantearse la hipótesis de una memoria que no olvide, si queremos llegar a una teoría de la Justicia” (Reyes, 2008, p. 104,).

La rememoración-la contemplación- en la conciencia- de las injusticias pasadas, o la investigación histórica no son suficientes a criterio de Benjamín. Para que la redención pueda producirse, es necesaria la reparación- en hebreo tikkun -del 
sufrimiento, de la desolación de las generaciones vencidas y el cumplimiento de los objetivos por los cuales lucharon y no lograron alcanzar (Lowy, 2003, p 59).

De inmediato las tesis nos hablan de la responsabilidad histórica que tiene el materialista histórico con la utopía social de los vencidos, si la visión de la historia es aquella de la lucha entre opresores y oprimidos la tarea no es solo la rememoración de las víctimas sino también la lucha porque su proyecto social sea realizado. "La redención mesiánica y revolucionaria es una misión que nos asignan las generaciones pasadas. No hay mesías enviado del cielo, nosotros mismos somos el mesías y cada generación posee parte del poder mesiánico que debe esforzarse por ejercer" (Lowy, 2003, p 59).

Se trata entonces de una Redención que se origina en la praxis colectiva de una humanidad, que desea liberarse del yugo que la ha mantenido esclava. "la redención es una auto-redención, cuyo equivalente profano podemos encontrar en Marx: "los hombres harán su propia historia y la emancipación de los trabajadores será obra de los trabajadores mismos". (Lowy, 2003, p 60).

La reparación colectiva y la rememoración de las víctimas del pasado son entonces los elementos a reivindicar por una generación que en el presente adquiere conciencia histórica sobre su pasado, deslegitimando así todo relato que excluya de la versión histórica a las víctimas, a los oprimidos, ya que esto constituye una forma de legitimar las Injusticias. Esto supone una transformación radical de la política con perspectiva de emancipación, que critica precisamente esas instancias desde donde surge la violencia y la dominación. El ejercicio de la memoria insinúa la necesidad de hacer del mundo una casa más humana, habitable e incluyente, capaz de abolir las desigualdades y defender la vida por encima de los intereses del poder.

Por otro lado las Victimas evidencian la ambigüedad ética de la ley al permitirnos constatar a través de la atención que reciben por parte de los Estados, las lógicas políticas que se piensan el camino hacia la reconciliación social, bajo la idea del perdón y la reparación del daño mediante indemnizaciones, remuneraciones económicas propias de la justicia del derecho, que concibe la Injusticia como una deuda que puede ser saldada con la legalidad, con el Derecho mismo, dejando de lado la dimensión ética, las causas que originan el daño, el contexto socio-político en el que surge y la reconstrucción de un tejido social fragmentado por los actos de violencia.

No se trata solo de rememorar, sino más bien, del uso de la Memoria como praxis política que exige a través de esa evocación del pasado que la barbarie no se vuelva repetir y que la justicia y la verdad puedan ser las garantes de esa no repetición. Veamos como el carácter de esta idea es reafirmado en la tesis III. 


\section{Tesis III}

El cronista que narra los acontecimientos, sin distinción entre los grandes y los pequeños, tiene en cuenta al hacerlo la siguiente verdad: de todo lo que sucedió alguna vez, nada debe considerarse perdido para la historia. Es cierto solo a la humanidad redimida pertenece plenamente su pasado. Esto significa que solo ella, en cada uno de sus momentos, puede citar su pasado. Cada uno de los instantes que ha vivido se convierte en una cita en la orden del día, y ese día es justamente el último. ((Benjamín en: Lowy, 2003, p. 62).

Se nos ha impuesto la creencia de que la Historia de la Humanidad ha sido un constante progreso, es muy común ver que de las victimas poco se hable, que de la catástrofe y las injusticias poco se cuestione, un ejemplo de ello es la Narrativa que se tiene en muchos países de América Latina sobre la llegada de los españoles. Las versiones sobre la conquista son la insinuación más descarada de superioridad de unas vidas sobre las otras para no hablar de "Razas". Poco se menciona sobre la barbarie a la que fueron sometidos miles y miles de indígenas, poco se habla de las extensas culturas y lenguas que desaparecieron a causa de aquel sometimiento atroz, es la historia a favor de los vencedores, y a partir de allí una vasta reproducción en el tiempo de valores y costumbres, de jerarquías e ideologías que nos siguen marcando hasta la actualidad tan ajenas o que poco se relacionan con lo que antaño fue una maravillosa cultura ancestral en la que por encima de cualquier cosa estaba la armonía con la naturaleza y el universo, un profundo respeto por la tierra y su conservación, una cultura arrasada por la irracionalidad de la barbarie.

Es por ello que nuevamente las tesis insisten en la acción redentora de la rememoración, hacer memoria de los hechos que la historia oficial consideró como insignificantes e irrelevantes, hacer memoria no solo para recordar que en épocas pretéritas la historia negó la existencia de las víctimas, sino también para comprender que el no haber detenido esa cadena de injusticias y muertes nos condena a seguir repitiendo los mismos errores políticos, sociales y éticos, "el pasado al que se refiere la memoria no es cualquier pasado. Es el pasado ausente, es decir, el que se refiere al sufrimiento del otro" (Zamora y Reyes Mate, (2011) P.29). De esta manera, reconociéndonos en el otro, nos reconocemos a nosotros mismos, como parte de una historia de luchas y resistencias que nos han querido ocultar.

Esa humanidad redimida de la que habla Benjamín en cada uno de sus momentos puede citar su pasado, pues en aras de transformar o de incidir políticamente en la sociedad es necesario recordarle a quienes la conforman, - y, que en muchas ocasiones padece una de las patologías sociales más graves en la actualidad "el olvido", -que sin justicia a las víctimas no es posible garantizar que el respeto por la vida sea posible. 
La redención, el juicio final de la tesis III, es entonces una apocatástasi ${ }^{3 i 4}$ en el sentido de que cada víctima del pasado, cada intento emancipatorio por humilde y pequeño que haya sido, quedará a salvo del olvido y será citado "en la orden del día" esto es, reconocido, honrado, rememorado (Lowy, 2003, p. 64).

\section{Tesis V}

El verdadero rostro de la historia se aleja al galope. Solo retenemos el pasado como una imagen que, en el instante mismo en que se deja reconocer, arroja una luz que jamás volverá a verse. "La verdad no se nos escapara": estas palabras de Gottfried Keller caracterizan con exactitud, en la imagen de la historia que se hacen los historicistas, el punto en que el materialismo histórico, a través de esa imagen, se abre paso. Irrecuperable, en efecto, es cualquier imagen del pasado que amenaza desaparecer con cada instante presente que, en ella, no se haya dado por aludido. (Benjamín en: Lowy, 2003 p, 71).

El historiador juega un papel importante a la hora de reconstruir el pasado, éste contribuye al proceso de creación de memoria histórica y a la consolidación de relatos culturales que serán aceptados por el resto de la sociedad como versión verdadera de su pasado y como base para la compresión del presente. La crítica benjaminiana al historicismo radica en que es precisamente el vencedor, los reyes, los poderosos quienes se han apoderado del tiempo histórico. Esta forma de narración del pasado se ha entregado a las causas nacionales, ha colaborado con la inserción de una comunidad en un relato político dominante que utiliza precisamente dicha versión histórica para crear simpatía y para seguir la secuencia de poder que siempre ha perseguido a sangre y fuego.

El materialista histórico es el sujeto que se atreve a desafiar esa versión del pasado y que la contrarresta aludiendo en cada momento, valga la redundancia, al pasado oculto que se esconde tras la institucionalización de la historia.

Es tan importante la figura del historiador y del narrador para Benjamín, porque es precisamente quien posee un discurso de verdad, capaz de modificar el ideario colectivo de las masas y, su importancia política, alcanza dimensiones hasta ahora insospechadas: "tanto el historiador como los gobernantes consideran, y quizá consideraron aún más, que la historia posee una importante misión que cumplir en el marco del Estado nación y es la de crear un relato unitario que defina lo que la nación es a través de su devenir temporal" (Bermejo (2002) p, 204) . La historia es en este sentido, en el sentido de esta utilización; un aparato de dominio ideológico. Es por ello que la reinterpretación de la Historia supone una

4 Pero la apocatástasis también significa, literalmente, el retorno de todas las cosas a su estado originario: en el evangelio, el restablecimiento del paraíso por el mesías.

Advocatus | No. 35: Julio - Diciembre 2020 | p.p. 197-207 | Universidad Libre Seccional Barranquilla 
erradicación si se quiere o un ataque directo a esos dispositivos ideológico-discursivos que garantizan la continuidad de la dominación y el mantenimiento del orden.

Benjamín insiste en la necesidad de parar ese continuum en el que cada hecho histórico debe dejar víctimas a su paso. Respecto a esto afirma Reyes Mate: "Estamos construyendo realmente la historia bajo la idea de que la historia se tiene que realizar con un costo humano y social (...) los cadáveres, los escombros son la parte natural de una historia. Entonces no hay que pararse a buscar una significación subjetiva de esa parte, sino que hay sencillamente que clasificarla como naturaleza”. (Zamora y Reyes Mate, 2011, p. 30).

Es por eso por lo que el filósofo "hace hincapié en el compromiso activo del partidario del materialismo histórico. Su objetivo es descubrir la constelación critica que tal o cual fragmento del pasado forma precisamente con tal o cual momento del presente" (Lowy, 2003, p. 72). Respecto a cómo ha de leerse el pasado Benjamín afirma en la tesis VI:

\section{Tesis VI}

Articular históricamente el pasado no significa conocerlo "tal como fue en concreto", sino más bien adueñarse de recuerdo semejante al que brilla en un instante de peligro. Corresponde al materialista histórico retener con firmeza esa imagen del pasado tal como esta se impone, de improviso, al sujeto histórico en el momento de peligro. El peligro amenaza tanto la existencia de la tradición como a quienes la reciben. Para una y para otros consiste en entregarlos como instrumentos a la clase dominante. En cada época es preciso intentar arrancar la tradición al conformismo que quiere apoderarse de ella. El mesías no viene solo como redentor, viene también como vencedor del anticristo. El don de atizar para el pasado la chispa de la esperanza solo toca en suerte al historiógrafo perfectamente convencido de que, si el enemigo triunfa, ni siquiera los muertos estarán seguros. Y ese enemigo no ha cesado de triunfar. (Benjamin en: Lowy, 2003, p. 75).

La tesis inicia rechazando la pretensión del historiógrafo historicista de narrar el pasado ratificando la versión de los reyes y los vencedores. Es por ello que Benjamin se piensa el pasado en destellos, un pasado que tiene vida y que solo puede recuperarse a través de la memoria.

"Pero hay otra manera de acercarse al pasado y esa es la que es propia de la Memoria. Historia y memoria, ambas se ocupan del pasado, pero la diferencia puede (y debe) ser radical: la mirada ha de ampliarse no solo a lo sucedido, sino también a lo que no acabó pasando porque fue derrotado, aniquilado, menospreciado, hundido, a lo que fue, en definitiva, malogrado. (Rivera y Bergalli, 2010. P. 29).

Manuel Reyes mate en su obra Media noche en la historia respecto al instante de peligro del que nos habla Benjamin afirmará: "La idea de fugacidad de la memoria queda

Advocatus | No. 35: Julio - Diciembre 2020 | p.p. 197-207 | Universidad Libre Seccional Barranquilla 
bien patente cuando añade que conocer el pasado es recordar en un instante de peligro" (Reyes Mate, 2006, p. 114), pues es la situación de peligro la que agudiza la mirada del lector de un texto o del pasado. Insiste que: el peligro está en ir contracorriente, es decir este historiador que desea darle vida a un pasado muerto, ausente, debe dar una batalla contra quienes nos han hecho creer que el muerto, muerto ésta y que no hay nada más que hacer por ellos. Lo que hace precisamente la memoria es salvar ese pasado de una segunda muerte, aquella "insignificancia hermenéutica" (Reyes Mate, 2006, p. 115), en la que, no solo han asesinado físicamente a las víctimas, sino que a su vez se ha querido eliminarlas de las memorias históricas, de la historia misma de la humanidad.

Como lo miramos anteriormente, Benjamin muy acertadamente afirma: "l don de atizar para el pasado la chispa de la esperanza solo toca en suerte al historiógrafo perfectamente convencido de que, si el enemigo triunfa, ni siquiera los muertos estarán seguros. Y ese enemigo no ha cesado de triunfar" (Benjamin en: Lowy, 2003, p. 75).

Es en el instante de peligro, cuando la imagen dialéctica brilla como un relámpago, el historiador o el revolucionario, debe dar pruebas de presencia de ánimo, para captar ese momento único, esa oportunidad fugaz y precaria de salvamento, antes de que sea demasiado tarde (Lowy, 2003, p. 76). Puesto que, como lo destaca la versión francesa de Benjamin, ese recuerdo, que se presenta en el momento de un peligro súbdito, puede ser precisamente lo que lo salva (GS, 1,2, p. 1263). (Lowy, 2003, p. 76).

Aparecen en esta tesis las figuras teológicas del mesías y el anticristo. Al respecto Rolf Tiedemann sostiene: "En ninguna otra parte Benjamin habla de manera tan directamente teológica como aquí, pero en ninguna otra parte tiene una intensión tan materialista" es preciso reconocer en el mesías a la clase proletaria, y en el anticristo a las clases dominantes.

En conclusión, ese instante de peligro que se nos presenta como un destello fugaz, en el cual nos encontramos con otra forma de conocer el pasado es lo que llamamos Memoria. Entendiendo como peligro aquello que amenaza acabar con la vida, peligro como el riesgo que se corre a causa de la violencia de las guerras, de las dictaduras, o de las leyes, peligro el ocultamiento de aquella verdad, su olvido.

Las víctimas en particular por la experiencia directa con la violencia a la que han sido sometidas comprenden que los mecanismos violentos y opresores que alguna vez les hicieron daño pueden hacerlo con cualquier individuo, pueblo y nación. En este sentido es donde hacer memoria cobra sentido e importancia, "La memoria es Resistencia a las barbaries" Halbwachs (2004), tal acción cuestiona la autoridad del presente, exige justicia y reparación y lo más importante para repensar una política sin víctimas y con las garantías para la no repetición de dichas violaciones. 
Esta propuesta benjaminiana de reinterpretar la historia, de cepillarla a contrapelo, de hacer una nueva lectura de aquel relato institucionalizado por el derecho como versión oficial del pasado, es una apuesta verdaderamente revolucionaria, una oportunidad capaz de transformar el ideario colectivo sobre lo que somos, sobre nuestra visión de sociedad y del otro, es el rescate de tradiciones y costumbres, de luchas y de sueños de libertad, de propuestas alternativas de cambio que en un momento de la historia se vieron atrofiadas por la violencia y el olvido.

Una posibilidad de justicia para los excluidos a los que nunca se les hizo justicia, puesto que la memoria se convierte en un ejercicio político capaz de anticipar grandes cambios sociales. La memoria es indudablemente una acción redentora, una práctica de la alteridad, un ejercicio ético, es la conciencia de los pueblos en la lucha por la justicia y la vida.

\section{REFERENCIAS}

- Bermejo, J.C. (2002). ¿Qué debo recordar? Los Historiadores y la configuración de la memoria. Navarra: Servicio de Publicaciones de la Universidad de Navarra.

- Bolívar, Echeverría, (2008). Walter Benjamín Tesis sobre la Historia y otros fragmentos. (Edición y traducción de Bolívar, E). México: U.A.C.M.

- Jaramillo Vélez, R. (1999). Homenaje a Walter Benjamín desde Colombia. Bogotá. Revista Argumentos, Universidad Nacional.

- Lowy, M. (2003) Walter Benjamín Aviso de incendio: una lectura de las tesis sobre el concepto de Historia. España: Fondo de cultura económica.

- Reyes, Mate. (2006), Media noche en la Historia. Comentarios a las tesis de Walter Benjamín "sobre el concepto de Historia". Madrid: Trotta.

- Rivera Bieras Iñaki y R. Bergalli (2011). La memoria: Categoría epistemológica para el abordaje de la historia y las ciencias penales, Crítica Penal y Poder.

- Zamora j, Reyes Mate. (2011). Justicia y Memoria, hacia una teoría de la Justicia anamnètica. Barcelona: Anthropos. 